\title{
GLOBAL CLIMATE CHANGE AS A NATIONAL SECURITY THREAT: AMERICAN AND RUSSIAN POLITICAL PRACTICES
}

\author{
Vladimir P. Nazarov \\ Security Council of the Russian Federation, Moscow, Russian Federation
}

Dmitry A. Afinogenov

Russian Presidential Academy of National Economy and Public Administration, Moscow, Russian Federation

\begin{abstract}
Introduction. The article gives an overview of American and Russian approaches to global climate change (GCC) in the context of the national security policy. The purpose of the study is to improve the national security policy in the context of GCC using international and Russian experience. The authors make proposals for refining Russian approaches to the problem including adjustments to the Russian Federation National Security Strategy, development of a number of other strategic planning documents and new initiatives to tackle threats related to GCC on a broad multilateral basis. Methods and methodology. The system analysis methods used in the research enable to reveal general trends in the evolvement of the GCC phenomenon and to predict its growing influence on governments and civil societies. The synthesis methods help to draw general conclusions that are common for the national security policies of all nations, to reveal the complex and interdisciplinary nature of GCC and to propose improvements in the government policies in this area. Analysis. The analysis of American official documents and scientific publications shows the evolution of approaches in assessing the GCC in relation to national security policies, whereas the GCC has been regarded as a threat to U.S. and international security and stability. The authors criticize unilateralism of American official approaches to threats posed by GCC as well as the ineffectiveness of collective attempts to counter these threats. Results. The study concludes that the GCC poses a common threat to humanity and requires collective concerted actions. It is therefore proposed that the long-term national interests be adjusted adding to their list the task of preserving the nature and environment, to clarify the strategic goal-setting in this critical area and to develop a forward-looking model for cooperation between the government, civil society and wildlife.
\end{abstract}

Key words: global climate change, national security threats, abnormal weather, natural and man-made disasters, national security strategy, strategic planning, strategic national priorities.

Citation. Nazarov V.P., Afinogenov D.A. Global Climate Change as a National Security Threat: American and Russian Political Practices. Vestnik Volgogradskogo gosudarstvennogo universiteta. Seriya 4. Istoriya. Regionovedenie. Mezhdunarodnye otnosheniya [Science Journal of Volgograd State University. History. Area Studies. International Relations], 2021, vol. 26, no. 1, pp. 107-122. (in Russian). DOI: https://doi.org/10.15688/jvolsu4.2021.1.10

\section{ГЛОБАЛЬНЫЕ ИЗМЕНЕНИЯ КЛИМАТА КАК УГРОЗА НАЦИОНАЛЬНОЙ БЕЗОПАСНОСТИ: АМЕРИКАНСКАЯ И РОССИЙСКАЯ ПОЛИТИЧЕСКИЕ ПРАКТИКИ}

\author{
Владимир Павлович Назаров \\ Совет безопасности Российской Федерации, г. Москва, Российская Федерация
}

Дмитрий Александрович Афиногенов

Российская академия народного хозяйства и государственной службы при Президенте Российской Федерации, г. Москва, Российская Федерация 
Аннотация. Введение. В статье рассматриваются современные американские и отечественные подходы к проблеме глобальных изменений климата (ГИК) в контексте политики в области обеспечения национальной безопасности, формулируется цель исследования - совершенствование политики обеспечения национальной безопасности в контексте глобального изменения климата с учетом международного и отечественного опыта. Сформулированы предложения относительно уточнения российских подходов к данной проблеме, в том числе за счет корректировки Стратегии национальной безопасности Российской Федерации, разработки ряда других документов стратегического планирования и подготовки инициатив по противодействию угрозам, связанным с климатическими изменениями, на широкой многосторонней основе. Memoдbl. Используемые методы системного анализа позволяют выявить общие тенденции в развитии феномена ГИК и спрогнозировать расширение его влияния на жизнь и деятельность государств и гражданского общества. Применение методов синтеза позволяет сформулировать общие выводы, характерные для политики обеспечения национальной безопасности всех стран, выявить комплексный и междисциплинарный характер проблемы ГИК и подготовить предложения по совершенствованию государственной политики в данной предметной области. Анализ. На основании анализа американских официальных документов и научных публикаций показана эволюция подходов к оценке ГИК применительно к политике обеспечения национальной безопасности, выявлено, что глобальные климатические изменения стали рассматриваться в качестве угрозы национальной безопасности США и международной безопасности и стабильности, сформулирован ряд критических замечаний относительно односторонности американских официальных подходов к угрозе ГИК и неэффективности коллективных попыток противодействовать ей. Результаты. По итогам исследования авторы констатируют, что проблема ГИК представляет общую угрозу человечеству и требует коллективных согласованных действий. В этой связи предлагается провести корректировку национальных интересов на долгосрочную перспективу, дополнив их перечень задачей сохранения природы и окружающей среды, уточнить стратегическое целеполагание в этой важнейшей сфере и сформировать перспективную модель взаимодействия государства, гражданского общества и живой природы. Вклад авторов. В.П. Назаровым разработана концепция исследования, проведен анализ зарубежных источников в области эволюции подходов в обеспечении национальной безопасности в условиях глобального изменения климата, дано обоснование комплексного и междисциплинарного характера проблемы ГИК. Д.А. Афиногенов провел анализ изъянов стратегического планирования в области обеспечения экологической безопасности Российской Федерации, внес предложения относительно уточнения российских подходов к данной проблеме, в том числе за счет корректировки документов стратегического планирования, формирования единого стратегического целеполагания по климатической повестке дня.

Ключевые слова: глобальные изменения климата, угрозы национальной безопасности, погодные аномалии, природные и техногенные катастрофы, стратегия национальной безопасности, стратегическое планирование, стратегические национальные приоритеты.

Цитирование. Назаров В. П., Афиногенов Д. А. Глобальные изменения климата как угроза национальной безопасности: американская и российская политические практики // Вестник Волгоградского государственного университета. Серия 4, История. Регионоведение. Международные отношения. - 2021. - Т. 26, № 1. C. 107-122.-DOI: https://doi.org/10.15688/jvolsu4.2021.1.10

Введение. Глобальные изменения климата являются комплексной проблемой социально-экономического, экологического и международного характера и в последние годы становятся важнейшим фактором в мировой политической и экономической повестке дня. Как отмечают эксперты, проблема ГИК сегодня является одной из центральных тем в деятельности ООН, занимает важное место в повестке наиболее влиятельных международных форумов, прежде всего «Группы восьми», в работе целого ряда негосударственных акторов, начиная с экологических организаций и заканчивая ведущими ТНК [15].
В силу своей многофакторности ГИК затрагивают практически все стороны и сферы жизнедеятельности человеческого общества, влияют на политику и экономику, выдвигают подчас совершенно новые условия к хозяйственной деятельности человека, особенно в высоких широтах, формируют новые угрозы и вызовы для мирового и отечественного здравоохранения, сельскохозяйственного производства, рационального природопользования, ставят новые задачи в сфере обеспечения обороны и безопасности.

Изменение климата - не новая тенденция. Под влиянием ряда глобальных естественных факторов, таких как дрейф конти- 
нентов, смещение оси Земли, извержения вулканов и воздействие океанических течений, климат на нашей планете постоянно менялся. Но это были длительные, охватывающие миллионы лет циклы изменений, составлявшие естественный фон развития жизни на земле. И только привнесенное человеком за последние полтора столетия антропогенное воздействие, которое в XX и XXI вв. стало главенствующим фактором, сыграло роль катализатора, ускорившего нарастание климатических проблем. Последние научные данные неопровержимо доказывают, что доминирующей причиной климатических изменений является антропогенное усиление парникового эффекта. Главный вывод: изменение климата - очень серьезная проблема, знания о его причинах достоверны $[4$, с. 6]. Поэтому вывод об антропогенной природе климатических изменений зафиксирован в решениях Всемирной метеорологической организации (BMO) [2], Парижском соглашении по климату 2015 г. [13], а также лег в основу политики России в области климата (Климатическая доктрина Российской Федерации) [3].

Одной из главных причин ГИК считается нарастание в атмосфере концентрации парниковых газов. Это привело к росту содержания диоксида углерода до 1,5-1,7 ppm в год, а концентрация углекислого газа возросла почти на $30 \%$ [18, с. 100]. По данным специалистов Океанографического института Скриппса (Сан-Диего) и Национального управления океанических и атмосферных исследований США, концентрация углекислого газа $\left(\mathrm{CO}_{2}\right)$ в земной атмосфере впервые в истории человечества превысила 415 частей на миллион (ppm) - то есть в каждом куб. м воздуха присутствует не менее 415 мл углекислого газа, или $0,041528 \%$ вместо 0,03\% в среднем дневном значении в доиндустриальную эпоху [5]. Предыдущий рекорд, по предположениям ученых, был установлен около 3 млн лет назад.

Как отмечалось в докладе ВМО о состоянии глобального климата в 2015-2019 гг., глобальная средняя температура с доиндустриального периода повысилась на $1,1^{\circ} \mathrm{C}$ и на 0,2 ${ }^{\circ} \mathrm{C}$ по сравнению с периодом 2011-2015 годов [2]. В целом, по данным ВМО, период с 2011 по 2020 г. станет самым теплым десятилетием за всю историю наблюдений, а са- мые теплые шесть лет - все годы начиная с 2015-го. Наиболее сложная ситуация отмечается в высоких широтах. В частности, по данным Росгидромета, в полярных регионах потепление идет со скоростью 0,7-0,8 градуса за десятилетие, иногда даже до 1 градуса [19].

Такая скорость наращивания глобального тепла вызывает серьезные опасения, так как провоцирует рост динамики глобального потепления в высоких широтах и влечет за собой множество проблем. Например, для Российской Федерации сокращение ареала вечной мерзлоты весьма значимо, так как он составляет $65 \%$ ее территории. На этих пространствах сосредоточено более половины мерзлых болот мира и $2 / 3$ запасов мерзлого метана, добывается более $90 \%$ природного газа и $75 \%$ нефти, создается до $70 \%$ стоимости экспорта страны [6, с. 15]. Отступление вечной мерзлоты ставит под угрозу условия хозяйствования, сложившиеся на этой территории.

По ряду экспертных оценок, в долгосрочной перспективе до 2100 г. ущерб от деградации многолетней мерзлоты из-за глобальных изменений климата может составить до $1,1-$ 1,2 \% мирового ВВП; для России до 2030 г. годовой ущерб только для зданий и сооружений от изменений климата в Арктике оценивается примерно в 200 млрд руб., или около 2,5 \% ВРП арктической зоны Российской Федерации [14, с. 16].

Правящие круги многих государств мира уже называют проблему ГИК новой глобальной угрозой, и сегодня в процесс изучения и прогнозирования последствий ГИК, оценки их возможного влияния на различные аспекты жизнедеятельности государства, экономики и общества все более вовлекаются органы государственной власти.

В этой связи целесообразность подготовки данной статьи обусловлена несколькими факторами. Во-первых, как справедливо отмечают некоторые исследователи, проблема ГИК междисциплинарна [8, с. 480], приобретает все новые измерения - технологические и технические, политические, организационные и нормативно-правовые, межстрановые - и превращается в весомый фактор в мировой политике. Во-вторых, проблема ГИК все чаще приобретает политическое измерение, стано- 


\section{СПЕЦСЛУЖБЫ И НАЦИОНАЛЬНАЯ БЕЗОПАСНОСТЬ}

вясь инструментом диктата и достижения преимуществ в недобросовестной конкуренции. И последнее - проблема ГИК имеет очевидное человеческое измерение, и ее решение зависит не только от системы природоохранных и природосберегающих мероприятий, экономики и политики, но и от изменения самой философии отношений человека и природы, так сказать - природосберегающего мышления.

Исходя из такого комплексного и междисциплинарного характера проблемы ГИК, задача данной статьи видится авторами в том, чтобы выделить основания для ее отнесения к новым угрозам национальной безопасности и сформулировать предложения по совершенствованию государственной политики в области обеспечения национальной безопасности и системы документов стратегического планирования в Российской Федерации.

Методы исследования. Для решения поставленной научной задачи важнейшее значение имеют исторический и системный методы. Рассмотрение процессов эволюции взглядов политики США по климатической повестке дня в строгой хронологической последовательности позволяет лучше понять сегодняшние аспекты решения проблем ГИК и то влияние, которое оказывают климатические факторы на политику безопасности. Ретроспективный анализ документов стратегического планирования Российской Федерации в сфере экологии позволяет вырабатывать предложения по уточнению архитектуры документов стратегического планирования, направленных на регулирование этой сферы деятельности.

Анализ массива документов в области ГИК показывает, что значительная часть таких исследований традиционно была сосредоточена на рассмотрении глобальных физических, космических, природных и экологических факторов. Вместе с тем под влиянием общего обострения международной обстановки и соперничества пришло понимание того, что проблема ГИК относится к разряду тех, где наука тесно сплетается с экономикой и политикой $[6$, с. 12]. Это существенно изменило сам методологический подход к решению климатических проблем, так как фактор климата стал использоваться политиками как сред- ство политической борьбы, удобный способ оказания давления на конкурентов и наращивания собственного экономического потенциала. Примерами таких действий могут служить сначала активное участие американской администрации при президенте Обаме в заключении в 2015 г. Парижского соглашения по климату, а затем выход США из него по решению президента Д. Трампа, заявившего, что он не хочет тратить «триллионы и триллионы долларов» и терять «миллионы и миллионы рабочих мест», чтобы бороться с потеплением [17].

В этой связи, касаясь вопроса методологии данного исследования, необходимо иметь в виду, что при рассмотрении проблемы ГИК с позиций обеспечения национальной безопасности представляется целесообразным сосредоточиться на анализе политической составляющей данного феномена и вопросах стратегического целеполагания, лежащих в основе практической политики в области безопасности. При этом наибольший интерес в плане изучения влияния фактора ГИК на официальные подходы к обеспечению национальной безопасности представляет собой опыт США.

Актуальность постановки данной научной задачи, помимо общих масштабов американской военной и экономической мощи, протяженности территории США, простирающейся по разнообразным природно-климатическим зонам, обусловливается прежде всего наличием достаточно развитой и в целом эффективной системы стратегического планирования и управления в области национальной безопасности. В связи с этим изучение американских подходов к оценке и анализу новых вызовов и угроз, их учету в формировании государственной политики в области обеспечения национальной безопасности представляет для нас не только научный, но и практический интерес.

Еще в 2015 г. президент США Б. Обама назвал изменения климата «серьезной угрозой глобальной безопасности» [35]. Эта оценка была основана на выводах американских ученых, согласно которым ГИК являются результатом воздействия антропогенных факторов - роста концентрации парниковых газов в атмосфере, в том числе на $40 \%$ - углекисло- 
го газа, образующегося при сжигании ископаемого топлива. Парниковые газы препятствуют отражению солнечной энергии, которая в результате во все возрастающей степени поглощается мировым океаном [29]. Следствием этого являются таяние ледников, участившиеся температурные рекорды, повышение уровня мирового океана, изменение погодных условий, в том числе количества осадков, в различных регионах мира, а также сокращение площади плодородных земель.

Рассмотрение американской политической элитой вопросов ГИК в контексте обеспечения национальной безопасности отражает серьезную эволюцию ее подходов к трактовке понятия «национальная безопасность». Если в 40-х гг. министр ВМС США Дж. Форрестол заявлял, что национальная безопасность «означает защиту страны от организованного насилия со стороны вооруженных иностранцев» [23], то в сегодняшнем сложном и взаимосвязанном мире, столкнувшемся с широким набором нетрадиционных угроз, таких как пандемии слабо изученных или новых заболеваний, ГИК, масштабные природные и техногенные катастрофы, американские политологи приходят к выводу о необходимости рассматривать понятие «национальная безопасность» в более широком контексте. Еще в 1983 г. известный американский политолог Ричард Аллман обосновал вывод о том, что определять национальную безопасность только с военной точки зрения - значит рисовать картину, очень далекую от реальности [39, c. 129]. Как отмечается в фундаментальной работе группы авторитетных американских политологов, политика в области национальной безопасности направлена на обеспечение безопасности населения, территории и образа жизни народа Соединенных Штатов, включая защиту от нападения на ее территорию и население, с целью обеспечить сохранение в неизменном виде основополагающих ценностей и институтов, содействовать продвижению этих ценностей и экономическому процветанию [21, с. 688].

Здесь следует заметить, что более широкий комплексный подход к задачам обеспечения национальной безопасности сегодня лежит и в основе российской политики в области национальной безопасности. Уместно на- помнить, что Стратегия национальной безопасности Российской Федерации определяет 9 стратегических национальных приоритетов, по которым выстраивается государственная политика в данной предметной области. Из них только два относятся к традиционным компонентам «жесткой силы» (оборона страны; государственная и общественная безопасность), остальные (повышение качества жизни российских граждан; экономический рост; наука, технологии и образование; здравоохранение; культура; экология живых систем и рациональное природопользование; стратегическая стабильность и равноправное стратегическое партнерство) являются задачами развития с учетом требований обеспечения национальной безопасности [12].

Дискуссия и анализ. После окончания холодной войны в американской правящей элите и академических кругах доминирует точка зрения о том, что состояние окружающей среды в мире в целом настолько серьезно затрагивает США, что его с полным основанием можно отнести к интересам национальной безопасности [22]. В редакции Стратегии национальной безопасности США 2010 г. отмечалось: «Угроза изменений климата является реальной, настоятельной и серьезной. Изменения, вызванные потеплением нашей планеты, приведут к новым конфликтам из-за потоков беженцев и нехватки ресурсов, страданиям от засухи и голода, ухудшениям качества земли повсюду в мире» [40]. В редакции Стратегии национальной безопасности 2015 г. уже была зафиксирована тесная взаимосвязь между ГИК и интересами национальной безопасности США, и министерству обороны, а также разведсообществу США даны конкретные поручения относительно реагирования на эту новую угрозу [36].

Американские исследователи называют целый ряд факторов воздействия ГИК на состояние национальной безопасности США.

Прежде всего, ГИК в перспективе могут существенно повлиять на задачи вооруженных сил и условия их применения [27]. В частности, в утвержденной в 2013 г. Национальной стратегии США для арктического региона указывается, что таяние льдов в акваториях арктической зоны потребует от вооруженных сил страны способности эффектив- 


\section{СПЕЦСЛУЖБЫ И НАЦИОНАЛЬНАЯ БЕЗОПАСНОСТЬ}

но действовать в этом регионе, особенно для обеспечения безопасности новых судоходных маршрутов в арктических водах или в случае возникновения конфликтов вокруг добычи природных ресурсов в районах, ранее считавшихся непригодными для экономической деятельности [41]. Соответственно, это ставит очень дорогостоящую задачу строительства дополнительных ледоколов, в том числе тяжелого класса, для нужд береговой охраны США. При этом стоимость только одного такого ледокола существенно превышает годовой бюджет закупок Службы береговой охраны США.

Кроме того, ожидаемые подъем уровня воды в Мировом океане, угрозы наводнений и ураганов неизбежно повлияют на планы военного строительства, в том числе касающиеся защиты объектов ВMC, расположенных преимущественно на береговой линии, критической инфраструктуры, включая энерго- и водоснабжение, транспорт и т. п. Прежде всего, это касается объектов Центрального командования ВС США (CENTCOM) со штабквартирой в г. Тампа и Южного командования (SOUTHCOM) в Майами, штат Флорида, а также целого ряда военных баз и представительств США за рубежом. Потребуется адаптация систем вооружений к более высоким температурам, погодным аномалиям и пр. [25]. Дополнительные задачи ожидают вооруженные силы и по линии проведения гуманитарных операций, поскольку ГИК могут приводить к стихийным бедствиям, массовой миграции людей из пострадавших районов, вспышкам инфекционных заболеваний, требовать ликвидации последствий погодных чрезвычайных ситуаций. Такие операции могут быть весьма масштабными, и к ним необходимо заблаговременно готовить личный состав. Так, например, в ликвидации последствий урагана «Катрина», который, по заключению экспертов, явился следствием ГИК, было задействовано около 70 тыс. военнослужащих США [23].

Кроме того, ГИК будут сопровождаться нарастанием региональных вооруженных конфликтов. Признаки этого можно наблюдать уже сейчас. По мнению экспертов, массовые протесты в Тунисе, повлекшие за собой «арабскую весну» в целом ряде стран Ближнего Востока, были спровоцированы удорожанием и нехваткой продовольствия вследствие сильной засухи в России в 2010 г., которая является основным поставщиком зерна в этот регион. Засуха, в свою очередь, объясняется экспертами воздействием ГИК [29]. Указывается также, что аномальные засухи 2006-2011 гг. способствовали началу гражданской войны в Сирии. По мнению американских политологов, причинно-следственная связь между ГИК, ростом бедности, радикализацией и насилием является очевидной и представляет собой угрозу интересам национальной безопасности США как мирового лидера [26].

По оценкам экспертов, к середине XXI в. ГИК и нехватка ресурсов могут заставить мигрировать в более благополучные страны миллионы людей, а к концу века - сотни миллионов. В этом плане особую угрозу для интересов национальной безопасности США представляет бедность в приграничной Мексике [36].

По заключению американских экспертов, все указанные обстоятельства ведут к «милитаризации» подходов правящих кругов США к проблемам ГИК в силу общей установки на гегемонию и единоличное лидерство, о чем свидетельствуют доклады Пентагона и президентские директивы последних лет [20].

Такой подход признается упрощенным и подвергается критике. Подчеркивается, что действительность гораздо сложнее шаблонных схем, которыми оперируют политики и военные. Отмечается, что засухи, наводнения и неурожаи действительно ведут к бедности, но не обязательно - к войне [33]. Массовый исход беженцев часто является следствием вооруженного конфликта, но не его причиной. Наоборот, нехватка ресурсов может даже стимулировать международное сотрудничество [38]. Так, например, разрушительное землетрясение в Непале в 2015 г. привело не к гражданской войне, а к политическому прорыву - окончанию длительной гражданской войны и проведению всенародных выборов [37].

Сильнейшее цунами в индонезийской провинции Ачех и дальнейшие масштабные усилия по ликвидации его последствий способствовали завершению длительной гражданской войны в регионе. Более того, многие защитники окружающей среды, пугающие обществен- 
ность катастрофическими последствиями ГИК, не замечают того, что в XXI в. сотни миллионов людей в развивающихся странах смогли преодолеть ужасающую нищету именно благодаря росту потребления угля и других невозобновляемых источников энергии.

Неоднозначно обстоит дело и с ядерной энергетикой. С одной стороны, ее развитие может обеспечить мир чистой энергией, что позволит добиться глубокой декарбонизации мировой экономики в исторически короткой перспективе - уже к середине столетия. $\mathrm{C}$ другой - атомная энергетика усилит риски распространения оружия массового уничтожения, которые могут представлять собой серьезнейшую угрозу мировой стабильности. Примечательно, что авторы «Бюллетеня ученыхатомщиков», создавшие виртуальные «часы судного дня», решительно выступают против варианта устранения угрозы глобального потепления за счет форсированного развития ядерной энергетики [30]. В то же время специалисты обращают внимание на то, что из 15 тыс. погибших в результате землетрясения и цунами в Японии в 2011 г. едва ли ктолибо умер, собственно, от утечки радиации на АЭС в Фукусиме. Между тем принятое под влиянием этой аварии руководством Японии и ФРГ решение свернуть производство электроэнергии на атомных станциях в пользу расширения угольной генерации стало причиной тысячи смертей от загрязнения воздуха [32].

Развивая концепцию неолиберального институционализма, которая обосновывает обеспечение национальной безопасности на принципах многосторонности, совершенствования международных институтов и правовых норм, взаимосвязи и взаимозависимости членов мирового сообщества в эпоху глобализации [31], современные американские сторонники кооперативных подходов к укреплению глобальной безопасности признают, что бедность действительно является самой серьезной предпосылкой внутренних конфликтов и гражданских войн. В то же время произошедший в последние 20-30 лет в странах третьего мира рост производства и доходов населения способствовал некоторому снижению числа вооруженных конфликтов в мире [24].

Таким образом, рост потребления угля в развивающихся странах в последние годы, с одной стороны, ускоряет процессы ГИК, но с другой - уменьшает риски вооруженных конфликтов и стабилизирует социально-экономическую ситуацию в целом ряде государств [34]. В связи с этим многие исследователи критически воспринимают заявления политиков и некоторых воинствующих экологов, которые обвиняют глобализацию, развитие промышленности и транспорта не только в ГИК, но и в конфликтах и войнах. Указывается на контрпродуктивность позиции администрации США, которая в своей политике делает упор на односторонние действия в ущерб поиску коллективных решений глобальных проблем.

В качестве примера можно назвать отношение Белого дома к Конвенции ООН по морскому праву 1982 года. Хотя в конгрессе, политических кругах и даже в военном руководстве США имеется немало сторонников присоединения к данной конвенции, администрация упорно отказывается от ее ратификации из-за позиции «ястребов», которые считают, что подобные договоры лишь сковывают Вашингтону руки и ущемляют суверенитет США. Между тем именно на пути участия в конвенции Соединенные Штаты могли бы урегулировать спорные вопросы, касающиеся разграничения континентального шельфа, развития судоходства и освоения природных ресурсов арктической зоны в условиях таяния льдов, избегая таким образом конфликтных ситуаций, чреватых вооруженными столкновениями [23].

Отсутствие лидерства со стороны Вашингтона подрывает эффективность коллективных усилий по противодействию глобальной угрозе изменений климата, способствуя, в частности, неудаче заключенного в 1997 г. Киотского протокола (предусматривает сокращение выбросов парниковых газов в атмосферу Земли) - самой значимой попытке решения проблемы ГИК на многосторонней основе. Главные споры возникают по вопросу о распределении ответственности и усилий по выполнению договоренностей, при этом разногласия наблюдаются не только по линии «Север - Юг», но и между ведущими развитыми странами. При этом Вашингтон игнорирует тот общеизвестный факт, что США ответственны за выпуск в атмосферу Земли около одной трети общего объема парниковых 
газов за период, начиная с 1850 года [20]. Хотя Международную конференцию по климату под эгидой ООН в 2015 г. в Париже можно расценить как шаг в правильном направлении, ее итоги представляют собой изложение общих намерений, но не твердые обещания. Последующие обсуждения пока не внесли ясность в затянувшиеся дискуссии о том, кто несет основную ответственность за парниковые выбросы, как осуществлять их сокращение и кто должен за это платить.

Таким образом, глобальное потепление как одно из основных последствий ГИК следует рассматривать в качестве реальной угрозы человеческой цивилизации. Становится все более очевидным, что в перспективе человечеству в целом в наибольшей степени угрожают не войны и оружие, а ожидаемое разрушительное воздействие ГИК. Такие хорошо известные последствия войн, как гибель и увечья, массовая миграция людей, голод, болезни, разрушение инфраструктуры и экономический спад, уже в обозримом будущем начнут происходить в результате усиливающихся погодных аномалий, таких как засуха, пожары, ураганы, таяние вечной мерзлоты. В дальнейшем возможен сценарий «перелома» в ГИК, при котором на смену потеплению придет похолодание с вероятным новым ледниковым периодом. Такая перспектива может представлять угрозу для человечества, сопоставимую с ужасами «ядерной зимы», которую ученые предсказывали в годы холодной войны.

Опасность реальна, хотя пока предвидится лишь в отдаленной перспективе. Политолог Массачусетского университета Дж. Голдстайн сравнивает нынешнюю ситуацию с приближением к Земле крупного небесного тела, столкновение с которым угрожает катастрофическими, хотя и не до конца понятными последствиями. В таком сценарии фактор времени имеет решающее значение: если до катастрофы остается, например, 3 года, ведущие державы, скорее всего, смогут объединиться перед лицом общей угрозы и использовать, например, свой ракетно-ядерный потенциал, чтобы заставить небесное тело свернуть с гибельного курса. Однако, если столкновение ожидается через 30 и более лет, организовать коллективный ответ будет гораздо сложнее. Именно такая ситуация наблюдается сегодня с ГИК [27].

Ряд американских политологов обращают внимание на то, что угрозе ГИК, как глобальной и требующей многосторонних усилий, пока уделяется явно недостаточное внимание. Исследование центральной проблемы - пути адаптации мирового сообщества к климатическим изменениям - часто подменяется изучением частных, но по существу второстепенных вопросов: поиску новых чистых источников энергии, защите окружающей среды прибрежных районов и т. п. Даже тема сохранения биоразнообразия и редких животных привлекает к себе гораздо больше внимания ученых, политиков и широкой общественности, чем поиск реалистичных и справедливых решений по магистральному направлению: как организовать широкое международное сотрудничество с целью выработки единой и эффективной программы действий мирового сообщества в условиях ГИК, которая предусматривала бы не технические и чисто экологические мероприятия, а фундаментальные политико-экономические решения, учитывала, что ГИК представляют собой результат нормальной экономической деятельности, в свое время обеспечившей индустриализацию развитым странам, а теперь позволяющей более бедным государствам преодолеть экономическую отсталость [28].

Отражением вакуума мысли на этом важнейшем для всего мира направлении может служить организованная в 2014 г. в НьюЙорке массовая демонстрация в защиту от глобального потепления, которая прошла с макетами подсолнухов вместо содержательных выступлений и конструктивных призывов, а основной лозунг поражал полным отсутствием смысла: «Изменить все можно только всем вместе» (англ. To change everything we need everyone).

Одним из вариантов выхода из сложившейся ситуации можно считать формирование системы адаптационного управления, так как, по оценкам экспертов, большинство неудач в ответах на современные климатические вызовы связано с ошибками управленческого характера. При этом особое значение приобретает стратегическое планирование, которое за рубежом рассматривается как важ- 
ная основа формирования системы адаптационного управления в арктических государствах в условиях климатических изменений. В частности, Е.Н. Никитина отмечает, что большинством стран либо приняты национальные стратегии адаптации к изменению климата, либо они включены в климатические планы действий. Так, разработаны специальные программы адаптации в полярных районах (национальная Программа адаптации к изменению климата для коренных народов севера Канады). Некоторые северные территории арктических стран осуществляют региональные планы действий по адаптации (Аляска в США, Тромсе в Норвегии); ряд регионов проводят совместные программы с соседними областями (совместная стратегия адаптации и партнерства между правительствами канадских провинций Юкон, Нунавут и Северо-Западных территорий). На Аляске и в Канаде действуют планы адаптации для отдельных поселений [11, с. 183-184].

Таким образом, проблемы ГИК, имеющие глобальное измерение и представляющие угрозу для международной стабильности и национальной безопасности большинства государств мира, пока еще решаются разрозненными усилиями различных стран и общественных организаций. На этом направлении отсутствуют согласованность, стратегическое целеполагание и лидерство, остро ощущается необходимость в новых инициативных подходах к решению всего комплекса текущих и перспективных задач.

Результаты. Изучение американских и иных зарубежных подходов к проблеме ГИК представляет для нашей страны серьезный практический интерес. Этому способствует внимание, которое сегодня уделяется мировым сообществом климатической повестке, а также то, что в России, как и в США, понятие «национальная безопасность» получает все более широкую трактовку, выходя за пределы чисто военных и внешнеполитических угроз и затрагивая информационную, экономическую, экологическую и другие сферы [10]. При этом фактор оценки состояния окружающей среды и изменения климата приобретает все более важное значение для российской политической практики. В частности, Президент Российской Федерации В.В. Путин, вы- ступая 22 октября 2020 г. на заседании дискуссионного клуба «Валдай», подробно остановился на вопросах окружающей среды. Глава государства подчеркнул, что тема охраны окружающей среды давно и прочно вошла во всемирную повестку. По его словам, природа крайне уязвима перед человеческой деятельностью, особенно по мере того, как эксплуатация земных ресурсов приобретает все более масштабный характер. Но и человек попрежнему не защищен от природных катаклизмов, многие из которых порождены именно антропогенным вмешательством. Кстати, по мнению ряда ученых, вспышки опасных болезней - это тоже ответ на подобное вторжение. Именно поэтому важно выстроить гармоничные отношения между человеком и природой. По мнению Президента России, «здесь уже накопилось критическое напряжение. Мы это видим по изменению климата. Эта проблема требует реальных действий и гораздо большего внимания» [16].

Учитывая, что изменение климата является одной из важнейших международных проблем XXI в., имеет комплексный междисциплинарный характер и охватывает экологические, экономические и социальные аспекты устойчивого развития Российской Федерации, в нашей стране еще в 2009 г. была принята Климатическая доктрина [3], а впоследствии выпущен целый ряд документов стратегического планирования, направленных на регулирование этой сферы деятельности и рациональное природопользование. В частности, политика государства в этой сфере реализуется через «Основы государственной политики в области экологического развития Российской Федерации на период до 2030 года», утвержденные Президентом России 30 апреля 2012 г., а также через Государственную программу Российской Федерации «Охрана окружающей среды» и национальный проект «Экология», утвержденные соответствующими постановлениями Правительства Российской Федерации. Эти документы стратегического планирования направлены на эффективное обращение с отходами производства и потребления, кардинальное снижение уровня загрязнения атмосферного воздуха в крупных промышленных центрах, в том числе уменьшение не менее чем на $20 \%$ совокупного объе- 
ма выбросов загрязняющих веществ в атмосферный воздух в наиболее загрязненных городах, повышение качества питьевой воды для населения и сохранение биологического разнообразия посредством создания не менее 24 новых особо охраняемых природных территорий.

Сам факт формирования национального проекта «Экология» свидетельствует о том, что впервые в новейшей истории России предпринята попытка сбалансированного решения социально-экономических и экологических задач, что соответствует принципам и целям устойчивого развития, которые приняты мировым сообществом на Саммите Организации Объединенных Наций в сентябре 2015 г. на период 2016-2030 годов [7, с. 7].

Безусловно, фактор ГИК необходимо учитывать при корректировке Стратегии национальной безопасности Российской Федерации, причем не только в части приоритетов «оборона страны» (в том числе за счет дополнительных мер по защите российских интересов в арктической зоне, укреплению защищенности военных объектов на побережье Северного Ледовитого и Тихого океанов) и «государственная и общественная безопасность» (дополнительные меры по предотвращению природных и техногенных катастроф и локализации их возможных последствий, гуманитарным операциям), но и по всем остальным стратегическим национальным приоритетам. При этом следует исходить из того, что в современных условиях для обеспечения суверенного и независимого развития России, способности противостоять внешнему санкционному давлению и проводить взвешенную и самостоятельную политику на мировой арене все большее значение приобретают компоненты «мягкой силы» в обеспечении национальной безопасности. Поэтому в ряду факторов, имеющих определяющее значение для достижения национальных целей развития России, вопросы экологии, формирования, в целом отвечающие современным реалиям стратегии взаимодействия общества и природы, являются одной из приоритетных задач государственной политики в области обеспечения национальной безопасности.

Исходя из этого, в ходе подготовки новой редакции Стратегии национальной безо- пасности Российской Федерации (а такая работа развернута в настоящее время) целесообразно произвести определенную корректировку национальных интересов на долгосрочную перспективу (пункт 30 Стратегии), дополнив их перечень задачей сохранения природы России и окружающего мира, создания комфортной среды обитания и хозяйственной деятельности. Соответственно, можно было бы скорректировать стратегические национальные приоритеты, а главное - усилить механизмы их реализации. Как отмечают эксперты, Стратегия национальной безопасности сформировала национальные приоритеты, но механизм их реализации до сих пор отсутствует, есть только инструменты мониторинга и оценки состояния национальной безопасности по каждому приоритету, которые не оказывают непосредственного воздействия на бюджетный процесс и государственные программы [1, с. 19].

В полной мере это утверждение можно отнести и к вопросам глобального изменения климата, рассматриваемым, как правило, в контексте проблем обеспечения экологической безопасности. В частности, реализация стратегического национального приоритета «экология живых систем и рациональное природопользование» осуществляется в рамках целого ряда программных и программно-плановых документов стратегического планирования, некоторые из них уже здесь упоминались. Национальный проект «Экология» peaлизуется в рамках четырех государственных программ (Государственная программа «Oxрана окружающей среды» на 2012-2020 годы, Государственная программа «Воспроизводство и использование природных ресурсов», Государственная программа «Развитие лесного хозяйства» на 2013-2020 годы, Государственная программа «Развитие рыбохозяйственного комплекса») и двух федеральных целевых программ, что не соответствует общему принципу проектного управления: одна цель (приоритет или национальный проект) - одна госпрограмма в совокупности со связанными подпрограммами - бюджетное планирование.

В этой связи представляется обоснованным ввести в практику государственного управления корректировку самого принципа формирования государственных программ Рос- 
сийской Федерации, имея в виду, что исполнительным (программно-плановым) документом по каждому стратегическому национальному приоритету (национальному проекту) является государственная программа. Соответственно, по каждому стратегическому национальному приоритету должен быть установлен единый набор документов стратегического планирования, включающий в себя прогноз, документ стратегического целеполагания (стратегию или доктрину), а также программно-плановый документ в виде государственной программы. При таком подходе государственная программа станет действительно работающим правовым и операционным инструментом Правительства Российской Федерации, прежде всего в части координации деятельности министерств и государственных компаний по достижению стратегических национальных приоритетов.

Масштабы возможных экономических последствий ГИК требуют совершенствования процесса стратегического планирования социально-экономического развития Российской Федерации и обеспечения национальной безопасности. В частности, одной из основных причин катастрофических наводнений считается неконтролируемая вырубка лесов и осушение болот. Лесные пожары и бесконтрольная лесозаготовительная деятельность в пойме притоков Амура в 2013 г. стали важным антропогенным фактором и одной из ключевых причин случившегося в регионе масштабного наводнения [9, с. 11]. Российская Федерация на примере борьбы с этим наводнением получила уникальный опыт комплексного подхода к ликвидации последствий такого рода стихийных бедствий. Однако стратегическая задача заключается в том, чтобы обеспечить планирование и координацию деятельности заинтересованных федеральных органов исполнительной власти, субъектов Российской Федерации, основных хозяйствующих субъектов по предупреждению чрезвычайных ситуаций, прогнозированию угроз и планированию профилактических мер, а также заблаговременной выработке алгоритма всестороннего взаимодействия при решении задач адаптации к глобальному изменению климата.

Такую работу еще предстоит наладить. Формат ее следует определить в Основах го- сударственной политики по проблемам стратегического планирования в Российской Федерации, разработка которых в настоящее время ведется. Принятие Основ позволит сформировать единую и сбалансированную систему документов стратегического планирования социально-экономического развития и обеспечения национальной безопасности в стране.

Безусловно, крайне важным является международное измерение политики, связанной с проблемами глобального изменения климата. Особого внимания требует выработка комплексных и научно обоснованных инициатив, с которыми Российская Федерация могла бы выступить на международной арене, в том числе в рамках $\mathrm{OOH}$, исходя из того, что климатические изменения представляют для человеческой цивилизации новую общую угрозу, которая, как и другие современные транснациональные вызовы, требует коллективных согласованных действий. Здесь необходимо учитывать несколько факторов.

Во-первых, данные инициативы должны укладываться в рамки Парижского соглашения по климату, имея в виду не глобальное регулирование в виде квот или других ограничений, как это предусматривает Киотский протокол, а приоритет мер, основанных на взаимовыгодной многосторонней кооперации.

Во-вторых, важно стремиться выработать общую позицию с другими членами ЕАЭС и БРИКС, чтобы не только придать нашим инициативам дополнительный - притом весьма существенный (!) - вес, но выступить на стороне тех государств, которые не несут основной ответственности за накопленный выброс парниковых газов.

Исходя из этого, одним из перспективных направлений объединения усилий в рамках комплексных и научно обоснованных инициатив могло бы стать формирование коллективной системы мониторинга и оценки эффективности результатов реализации мероприятий по адаптации экономик и гражданского общества к изменениям климата и смягчению их последствий. Такой мониторинг позволит комплексно рассматривать новые вызовы и угрозы для систем здравоохранения и социальной защиты заинтересованных стран, обеспечит сбалансированность распределения ресурсов, даст возможность максимально эф- 
фективно использовать природные и географические особенности, возможности экономического положения всех участников соглашения для выработки и реализации действенных мер по борьбе с ГИК.

Необходимо также сформировать новую перспективную модель взаимодействия государства, гражданского общества и живой природы и на этой основе выйти на единое стратегическое целеполагание в сфере природосбережения, экологической безопасности и сохранения климата. Подход, основанный на рассмотрении проблемы ГИК как новой глобальной угрозы национальной и международной безопасности, позволит придать конструктивную направленность нынешним, зачастую противоречивым и разноплановым международным дискуссиям на климатическую тему и перейти от голословных призывов «изменить все» в духе Греты Тунберг к выработке практических решений по таким основополагающим вопросам, как инновации в энергетике, ценообразование на углеродное топливо и налогообложение, распределение обязанностей и договорных обязательств между «Севером» и «Югом», производителями и потребителями энергии и т. п.

Академическое сообщество, хорошо понимающее реальную ситуацию с ГИК, с одной стороны, и особенности современной мировой обстановки, возможности международных институтов и правовых норм - с другой, способно предложить коллективные меры противодействия этой новой угрозе человеческой цивилизации, разделенной на большое число суверенных государств.

\section{СПИСОК ЛИТЕРАТУРЫ}

1. Афиногенов, Д. А. О некоторых неотложных задачах по совершенствованию государственной политики в области стратегического планирования / Д. А. Афиногенов, В. П. Назаров // Власть. 2020. - T. 29, № 2. - С. 17-26.

2. Климат и безопасность. Глобальный климат в 2015-2019 годах: изменение климата набирает темп // Всемирная Метеорологическая Организация. Электрон. текстовые дан. - Режим доступа: https:// public.wmo.int/ru/media/пресc-релизы/глобальныйклимат-в-2015-2019-годах-изменение-климата-набирает-темп (дата обращения: 02.12.2020). - Загл. с экрана.
3. Климатическая доктрина Российской Федерации. - Электрон. текстовые дан. - Режим доступа: http://kremlin.ru/events/president/news/6365 (дата обращения: 02.12.2020). - Загл. с экрана.

4. Кокорин, А. О. Обзор доклада Николаса Стерна «Экономика изменения климата». - Изд. 2-е, доп. и перераб. / А. О. Кокорин, С. Н. Кураев // WWF, Strategic Programme Fund (SPF). - M. : WWF России, 2009. - 60 с. - Электрон. текстовые дан. - Режим доступа: https://infoik.net.kg/images/files/economy.pdf (дата обращения: 02.12.2020). - Загл. с экрана.

5. Концентрация углекислого газа в атмосфеpe Земли достигла исторического максимума. Электрон. текстовые дан. - Режим доступа: https:// tass.ru/obschestvo/6423526 (дата обращения: 02.12.2020). - Загл. с экрана.

6. Корзун, В. А. Изменение климата: причины, прогнозы, возможные последствия для мировой экономики / В. А. Корзун. - М. : ИМЭМО РАН, 2012. $-61 \mathrm{c}$.

7. Краснощеков, В. Н. Оценка эффективности реализации национального проекта «Экология» / В. Н. Краснощеков, Д. Г. Ольгаренко // Природообустройство. - 2019. - № 2. - С. 6-12.

8. Макаров, И. А. Глобальное изменение климата как вызов мировой и экономической науке / И. А. Макаров // Экономический журнал ВШЭ. 2013. - № 3. - С. 479-496.

9. Махинов, А. Н. Наводнение в бассейне Амура 2013 года: причины и следствия / А. Н. Махинов, В. И. Ким, Б. А. Воронов // Вестник Дальневосточного отделения РАН. - 2014. - № 2. - С. 5-14.

10. Назаров, В. П. Проблемы развития общей теории национальной безопасности в контексте корректировки Стратегии национальной безопасности Российской Федерации / В. П. Назаров, Д. А. Афиногенов // Власть. - 2020. - Т. 28, № 1. - С. 9-26.

11. Никитина, Е. Н. Изменение климата в Арктике: адаптация в ответ на новые вызовы / Е. Н. Никитина // Контуры глобальных трансформаций: политика, экономика, право. - 2019. - № 5. - С. 177-200.

12. «О Стратегии национальной безопасности Российской Федерации» : указ Президента Российской Федерации от 31.12.2015 № 683. - Электрон. текстовые дан. - Режим доступа: http://www. consultant.ru/document/cons_doc_LAW_191669 (дата обращения: 02.12.2020). - Загл. с экрана.

13. Парижское соглашение. 2015 / Организация объединенных наций. - Электрон. текстовые дан. Режим доступа: https://unfccc.int/files/essential background/convention/application/pdf/russian paris_agreement.pdf (дата обращения: 02.12.2020).Загл. с экрана.

14. Последствия изменения климата для экономического роста и развития отдельных секторов экономики российской Арктики / Б. Н. Порфирьев, 
С. А. Воронина, В. В. Семикашев, Н. Е. Терентьев // Арктика: экология и экономика. - 2017. - № 4 (28). C. 4-17.

15. Русакова, Ю. А. Проблема изменения климата в мировой политике / Ю. А. Русакова // Власть. 2010. - № 7. - С. 129-130.

16. Стенограмма: О чем рассказал Владимир Путин на заседании клуба «Валдай». - Электрон. текстовые дан. - Режим доступа: https://rg.ru/2020/ 10/22/stenogramma-o-chem-rasskazal-vladimir-putinna-zasedanii-kluba-vaddaj.html (дата обращения: 02.12.2020). - Загл. с экрана.

17. Трамп: Я не намерен тратить «триллионы» долларов на предотвращение глобального потепления. - Электрон. текстовые дан. - Режим доступа: https://bulgartimes.com/tramp-ya-ne-nameren-tratittrilliony-dollarov-na-predotvrashhenie-globalnogopotepleniya/ (дата обращения: 02.12.2020). - Загл. с экрана.

18. Уварова, Н. Н. Климат как глобальная проблема: прошлое, настоящее, будущее / Н. Н. Уварова // Успехи современного естествознания. - 2006. № 4. - С. 100-102.

19. Фантастический 2020-й: погода ставит рекорды даже в Арктике. - Электрон. текстовые дан. - Режим доступа: https:/www.kp.ru/daily/217189/4296164/ (дата обращения: 02.12.2020). - Загл. с экрана.

20. Ajir, M. An Uncertain Future's Implications on United States National Security / M. Ajir. University of Nebraska-Omaha. May $1^{\text {st }}, 2016$. Electronic text data. - Mode of access: https:// www.researchgate.net/publication/303721124_An Uncertain Future\%27s Implications on United_States_National_Security (date of access: 02.12.2020). - Title from screen.

21. American National Security / A. A. Jordan, W. J. Taylor Jr., M. J. Meese, S. C. Neilsen. - Baltimore : Johns Hopkins University, 2011. - 688 p.

22. Barnett, J. Environmental Security/ J. Barnett // The Routledge Handbook of New Security Studies / J. Peter Burgess, ed. - New York : Routledge, 2010. P. 123-131.

23. Busby, J. Who cares about the weather?: Climate change and U.S. national security / J. Busby // Security Studies. - 2008. - Vol. 17 (3). - P. 468-504.

24. Fearon, J. D. Economic Development, Insurgency, and Civil War / J. D. Fearon // Institutions and Economic Performance/ ed.: E.Helpman.-Cambridge, MA:Harvard University Press, 2008. - P. 75-90.

25. Findings from Select Federal Reports: The National Security Implications of a Changing Climate. White House. 2015. - Electronic text data. - Mode of access: https://www.whitehouse.gov/sites/default/ files/docs/national security implications of changing_climate_final_051915_embargo.pdf(date of access: 08.11.2020). - Title from screen.
26. Fountain, H. Researchers Link Syrian Conflict to a Drought Made Worse by Climate Change / H. Fountain // The New York Times. - 2015. - March 2.

27. Goldstein, J. S. Climate Change as a Global Security Issue / J. S. Goldstein // Journal of Global Security Studies. - 2016. - Vol. 1, iss. 1 (February). - P. 95-98. Electronic text data. - Mode of access: https://doi.org/ 10.1093/jogss/ogv010 (date of access: 08.11.2020). - Title from screen.

28. Javeline, D. The Most Important Topic Political Scientists Are Not Studying: Adapting to Climate Change / D. Javeline // Perspectives on Politics. - 2014. - Vol. 12. - P. 420-434.

29. Johnstone, S. Global Warming and the Arab Spring / S. Johnstone, J. Mazo // Survival: Global Politics and Strategy. - 2011. - Vol. 53 (2). - P. 11-17.

30. Kennette, B. Doomsday Clockwork / B. Kennette // Bulletin of the Atomic Scientists. Electronic text data. - Mode of access: http:// thebulletin.org/doomsday-clockwork8052 (date of access: 18.11.2020). - Title from screen.

31. Keohane, R. O. The Global Politics of Climate Change: Challenge for Political Science/ R. O. Keohane // PS: Political Science \& Politics. - 2015. - Vol. 47. P. 19-26.

32. Kharecha, P. Prevented Mortality and Greenhouse Gas Emissions from Historical and Projected Nuclear Power / P. A. Kharecha, J. E. Hansen // Environmental Science and Technology. - 2013. Vol.47. - P. 4889-4895. - DOI: 10.1021/es3051197.

33. Moran, D. Climate Change and National Security: A Country-Level Analysis / D. Moran. Washington, DC : Georgetown University Press, 2011. -320 p.

34. Nordhaus, W. The Climate Casino: Risk, Economics, and Uncertainty for a Warming World / W. Nordhaus. - New Haven, CT : Yale University Press, 2013. -378 p.

35. Obama, B. Address at Coast Guard Academy. New London, CT, May 20, 2015 / B. Obama. Electronic text data. - Mode of access: https://www. whitehouse.gov/the-press-office/2015/05/20/ remarks-president-united-states-coast-guard-academycommencement (date of access: 18.11.2020). - Title from screen.

36. O'Sullivan, T. Defining and Distinguishing Homeland from National Security and Climate-Related Environmental Security, in Theory and Practice / T. M. O'Sullivan, J. Ramsay // Journal of Homeland Security and Emergency Management. - 2015. Vol. 12 (1). - P. 43-66.

37. Sharma, B. Earthquake Prods Nepal Parties to Make Constitutional Deal / B. Sharma, E. Barry // The New York Times. - 2015. - June 9.

38. Shlomi, D. Beyond Resource Wars: Scarcity, Environmental Degradation, and International 
Cooperation / D. Shlomi. - Cambridge, MA : MIT Press, 2011. $-378 \mathrm{p}$.

39. Ullman, R. H. Redefining security/R. H. Ullman // International security. - 1989. - Vol. 8 (1). - P. 129-153.

40. White House. National Security Strategy, 2011. - Electronic text data. - Mode of access: https:// www.whitehouse.gov/sites/default/files/rss_viewer/ national_security_strategy.pdf (date of access: 11.11.2020). - Title from screen.

41. White House. National Strategy for the Arctic Region, 2013. - Electronic text data. - Mode of access: https:/www.whitehouse.gov/sites/default/files/docs/ nat_arctic_strategy.pdf(date of access: 11.11.2020). Title from screen.

\section{REFERENCES}

1. Afinogenov D.A., Nazarov V.P. O nekotoryh neotlozhnyh zadachah po sovershenstvovaniyu gosudarstvennoy politiki v oblasti strategicheskogo planirovaniya [Some Urgent Tasks to Improve Public Policy on Strategic Planning]. Vlast, 2020, vol. 29, no. 2, pp. 17-26.

2. Klimat i bezopasnost. Globalniyklimat v 20152019 godah: izmenenie klimata nabiraet temp [Climate and Security. Global Climate in 2015-2019: Climate Change Is Gaining Tempo]. Vsemirnaya Meteorologicheskaya Organizatsiya [World Meteorological Organization]. URL: https://public. wmo.int/ru/media/пресc-релизы/глобальный-климат-в-2015-2019-годах-изменение-климата-набирает-темп (accessed 2 December 2020).

3. Klimaticheskaya doktrina Rossiyskoy Federatsii [Climate Doctrine of the Russian Federation]. URL: http://kremlin.ru/events/president/ news/6365 (accessed 2 December 2020).

4. Kokorin A.O., Kurayev S.N. Obzor doklada Nikolasa Sterna «Ekonomika izmeneniya klimata» [Nicolas Stern's Report Review. Economy of Climate Change]. WWF, Strategic Programme Fund (SPF). Moscow, WWF Rossii, 2009. 60 p. (accessed 2 December 2020).

5. Kontsentratsiya uglekislogo gaza v atmosphere Zemli dostigla istoricheskogo maksimuma [Concentration of Carbon Dioxide in the Earth's Atmosphere Reached Historic Maximum]. URL: https://tass.ru/obschestvo/6423526 (accessed 2 December 2020).

6. Korzun V.A. Izmemenie klimata: prichiny, prognozy, vozmozhnye posledstviya dlya mirovoy ekonomiki [Climate Change: Causes, Forecasts, Possible Consequences for the World Economy]. Moscow, IMEMO RAN, 2012.61 p.

7. Krasnoshchekov V.N., Ol'garenko D.G. Otsenka effektivnosti realizatsii natsionalnogo proekta
«Ekologiya» [Evaluation of the Effectiveness of Realization of the National Project "Ecology"]. Prirodoobustroystvo, 2019, no. 2, pp. 6-12.

8. Makarov I.A. Global'noye izmenenie klimata kak vyzov mirovoy i ekonomicheskoy nauke [Global Climate Change as a Challenge to the Global Economy and Economic Science]. Ekonomicheskiy zhurnal VShE, 2013, no. 3, pp. 479-496.

9. Mahinov A.N., Kim V.I., Voronov B.A. Navodneniye v basseyne Amura 2013 goda: prichiny i sledstviya [The Amur 2013 Basin Flood: Causes and Consequences]. Vestnik Dalnevostochnogo otdeleniya RAN, 2014, no. 2, pp. 5-14.

10. Nazarov V.P., Afinogenov D.A. Problemy razvitiya obshchey teorii natsional'noy bezopasnosti v kontekste korrektirovki Strategii natsional'noy bezopasnosti Rossiyskoy Federatsii [Problems of the Development of the General Theory of National Security in the Context of the Adjustment of the National Security Strategy of the Russian Federation]. Vlast, 2020, vol. 28, no. 1, pp. 9-26.

11. Nikitina E.N. Izmenenie klimata v Arktike: adaptatsiya $\mathrm{v}$ otvet na novye vyzovy [Climate Change in the Arctic: Adaptation in Reply to New Challenges]. Kontury global'nyh transformatsiy: politika, ekonomika, pravo, 2019, no. 5, pp. 177-200.

12. «O Strategii natsional'noy bezopasnosti Rossiyskoy Federatsii»: ukaz Prezidenta Rossiyskoy Federatsii ot 31.12.2015 № 683 [National Security Strategy of the Russian Federation. Decree of the President of the Russian Federation, December 31, 2015, no. 683]. URL: http:// www.consultant.ru/ document/cons_doc_LAW_191669 (accessed 2 December 2020).

13. United Nations. Parizhskoe soglashenie. 2015 [Paris Agreement. 2015]. URL: https://unfccc. int/ files/essential_background/convention/application/ pdf/russian_paris_agreement.pdf (accessed 2 December 2020).

14. Porfir'yev B.N., Voronona S.A., Semikashev V.V., Terent'yev N.E. Posledstviya izmeneniya klimata dlya ekonomicheskogo rosta i razvitiya otdel'nyh sektorov ekonomiki rossiyskoy Arktiki [Impact of Climate Change on Economic Growth and Development of Selected Sectors of the Russian Arctic Economy]. Arktika: ekologiya i ekonomika, 2017, no. 4 (28), pp. 4-17.

15. Rusakova Yu.A. Problema izmeneniya klimata $\mathrm{v}$ mirovoy politike [The Issue of Climate Change in World Politics]. Vlast, 2010, no. 7, pp. 129-130.

16. Stenogramma: O chem rasskazal Vladimir Putin na zasedanii kluba «Valday» [Transcript: What Vladimir Purin Told at the Meeting of the Club "Valgai"]. URL: https://rg.ru/2020/10/22/stenogramma-o-chemrasskazal-vladimir-putin-na-zasedanii-kluba-vaddaj. html (accessed 2 December 2020). 
17. Tramp: Ya ne nameren tratit' "trilliony» dollarov na predotvrashchenie global'nogo potepleniya [Trump: I Do Not Intend to Spend "Trillions" of Dollars to Prevent Global Warming]. URL: https://bulgartimes.com/tramp-ya-ne-nameren-tratittrilliony-dollarov-na-predotvrashhenie-globalnogopotepleniya/ (accessed 2 December 2020).

18. Uvarova N.N. Klimat kak global'naya problema: proshloye, nastoyashchee i budushchee [Climate as a Global Problem: Past, Present, Future]. Uspehi sovremennogo estestvoznaniya, 2006, no. 4, pp. 100-102.

19. Fantasticheskiy 2020-y: pogoda stavit rekordy dazhe v Arktike [Fantastic 2020: The Weather Sets Records Even in the Arctic]. URL: https:// www.kp. ru/daily/217189/4296164/ (accessed 2 December 2020).

20. Ajir M. An Uncertain Future's Implications on United States National Security. University of Nebraska-Omaha. May 1 ${ }^{\text {st }}, 2016$. URL: https://www. researchgate.net/publication/303721124_An Uncertain_Future\%27s_Implications_on_United_States National_Security (accessed 2 December 2020).

21. Jordan A.A., Taylor W.J., Jr., Meese M.J., Neilsen S.C. American National Security. Baltimore, Johns Hopkins University, 2011. 688 p.

22. Barnett J. Environmental Security. Burgess J.P., ed. The Routledge Handbook of New Security Studies. New York, Routledge, 2010, pp. 123-131.

23. Busby J. Who Cares About the Weather?: Climate Change and U.S. National Security. Security Studies, 2008, vol. 17 (3), pp. 468-504.

24. Fearon J.D. Economic Development, Insurgency, and Civil War. Helpman E., ed. Institutions and Economic Performance. Cambridge, MA, Harvard University Press, 2008, pp. 75-90.

25. Findings from Select Federal Reports: The National Security Implications of a Changing Climate. White House. 2015. URL: https://www. whitehouse.gov/sites/default/files/docs/national_ security_implications_of_changing_climate_final_ 051915_embargo.pdf(accessed 8 November 2020).

26. Fountain H. Researchers Link Syrian Conflict to a Drought Made Worse by Climate Change. The New York Times, 2015, March 2.

27. Goldstein J.S. Climate Change as a Global Security Issue. Journal of Global Security Studies, 2016, vol. 1, iss. 1 (February), pp. 95-98. URL: https://doi.org/ 10.1093/jogss/ogv010 (accessed 8 November 2020).
28. Javeline D. The Most Important Topic Political Scientists Are Not Studying: Adapting to Climate Change. Perspectives on Politics, 2014, vol. 12, pp. 420-434.

29. Johnstone S., Mazo J. Global Warming and the Arab Spring. Survival: Global Politics and Strategy, 2011, vol. 53 (2), pp. 11-17.

30. Kennette B. Doomsday Clockwork. Bulletin of the Atomic Scientists. URL: http://thebulletin.org/ doomsday-clockwork8052 (accessed 18 November 2020).

31. Keohane R.O. The Global Politics of Climate Change: Challenge for Political Science. PS: Political Science \& Politics, 2015, vol. 47, pp. 19-26.

32. Kharecha P.A., Hansen J.E. Prevented Mortality and Greenhouse Gas Emissions from Historical and Projected Nuclear Power. Environmental Science and Technology, 2013, vol. 47, pp. 4889-4895. DOI: $10.1021 / \mathrm{es} 3051197$.

33. Moran D. Climate Change and National Security: A Country-Level Analysis. Washington, DC, Georgetown University Press, 2011. 320 p.

34. Nordhaus W. The Climate Casino: Risk, Economics, and Uncertainty for a Warming World. New Haven, CT, Yale University Press, 2013. 378 p.

35. Obama B. Address at Coast Guard Academy. New London, CT, May 20, 2015. URL: https://www. whitehouse.gov/the-press-office/2015/05/20/remarkspresident-united-states-coast-guard-academycommencement (accessed 18 November 2020).

36. O’Sullivan T.M., Ramsay J. Defining and Distinguishing Homeland from National Security and Climate-Related Environmental Security, in Theory and Practice. Journal of Homeland Security and Emergency Management, 2015, vol. 12 (1), pp. 43-66.

37. Sharma B., Barry E. Earthquake Prods Nepal Parties to Make Constitutional Deal. The New York Times, 2015, June 9.

38. Shlomi D. Beyond Resource Wars: Scarcity, Environmental Degradation, and International Cooperation. Cambridge, MA, MIT Press, 2011.378 p.

39. Ullman R.H. Redefining Security. International Security, 1989, vol. 8 (1), pp. 129-153.

40. White House. National Security Strategy, 2011. URL: https://www.whitehouse.gov/sites/ default/files/rss_viewer/national_security_ strategy. pdf(accessed 11 November 2020).

41. White House. National Strategy for the Arctic Region, 2013. URL: https://www.whitehouse.gov/ sites/default/files/docs/nat_arctic_strategy.pdf (accessed 11 November 2020). 


\section{Information About the Authors}

Vladimir P. Nazarov, Candidate of Sciences (Politics), Advisor to the Secretary, Security Council of the Russian Federation, Ilyinka St, 23/16, 103132 Moscow, Russian Federation, vlnazarov1950@gmail.com, https://orcid.org/0000-0002-6290-8220

Dmitry A. Afinogenov, Doctor of Sciences (Politics), Professor, Department of Public Administration and National Security, Institute of Law and National Security, Russian Presidential Academy of National Economy and Public Administration, Prosp. Vernadskogo, 82, 119571 Moscow, Russian Federation, afinogenov_d@inbox.ru, https://orcid.org/0000-0003-3558-3122

\section{Информация об авторах}

Владимир Павлович Назаров, кандидат политических наук, советник секретаря, Совет безопасности Российской Федерации, ул. Ильинка, 23/16, 103132 г. Москва, Российская Федерация, vlnazarov1950@gmail.com, https://orcid.org/0000-0002-6290-8220

Дмитрий Александрович Афиногенов, доктор политических наук, профессор кафедры государственного управления и национальной безопасности, Российская академия народного хозяйства и государственной службы при Президенте Российской Федерации, просп. Вернадского, 82, 119571 г. Москва, Российская Федерация, afinogenov_d@inbox.ru, https://orcid.org/0000-0003-3558-3122 